\title{
Matching seedling size to planting conditions: interactive response with soil moisture
}

\author{
Juan A Oliet ${ }^{(1)}$, \\ Esther Ortiz de Urbina ${ }^{(1)}$, \\ Martina Sánchez-Pinillos ${ }^{(2)}$, \\ Guillermo Tardío-Cerrillo ${ }^{(1)}$
}

\begin{abstract}
Seedling size is a very important issue when producing plants for restoration projects. Scientific evidence on the appropriate size for drylands is contradictory. Thus, the aim of this study was to evaluate the effect of seedling size during first establishment by conducting a short term greenhouse experiment with Pinus canariensis containerized seedlings. A selection of large (mean height: $33.7 \mathrm{~cm}$ ) and small $(14.3 \mathrm{~cm}$ ) one-year-old seedlings were planted in pots under two volumetric water content regimes: dry (7\%) and wet $(15 \%)$. Midday shoot water potential was measured in two periods: 10 (prior to root protrusion) and 30 (once the roots had protruded from the plug) days after planting. The length of protruding roots was measured after 30 days. One month after planting, the large seedlings under the dry regime produced more new roots than the small seedlings, but also showed the highest midday water potential values. Therefore, the greater root growth of the former did not offset the higher transpiration demand when planted in dry soils. These results suggest that under uncertainty about the soil humidity levels of dry areas, using small seedlings can improve their short-term survival after planting.
\end{abstract}

Keywords: Planting Survival, Root Water Uptake, Seedling Size, Seedling Ecophysiology, Transpiration Demand, Water Potential, Seedling Morphology biome, an ecophysiological model stressing the importance of nutrients and carbohydrate remobilization and photosynthesis for root growth has been developed to explain why large seedlings survive better (Villar-Salvador et al. 2012). However, in very dry areas, or during dry planting years when access to water is uncertain, the most appropriate seedling size for planting continues to be a matter of debate. Under these environmental conditions, planting small seedlings is considered to be a conservative strategy that can be expedient insofar as planting shock is reduced by minimizing shoot water losses (Lamhamedi et al. 1997, Trubat et al. 2010, Cortina et al. 2013, Ovalle et al. 2016). Notwithstanding this, the specific literature on dry areas is somewhat contradictory, with studies showing that seedling size has positive (Puértolas et al. 2012, Villar-Salvador et al. 2012, 2013b, Oliet et al. 2013, Tsakaldimi et
(1) Escuela Técnica Superior de Ingeniería de Montes, Forestal y del Medio Natural, Universidad Politécnica de Madrid, Ciudad Universitaria, 28040 Madrid (Spain); (2) Forest Sciences Centre of Catalonia (CEMFOR-CTFC), 25280 Solsona (Spain)

@ Juan A Oliet (juan.oliet@upm.es)

Received: Mar 29, 2018 - Accepted: Feb 22, 2019

Citation: Oliet JA, Ortiz de Urbina E, Sánchez-Pinillos M, Tardío-Cerrillo G (2019). Matching seedling size to planting conditions: interactive response with soil moisture. iForest 12: 220225. - doi: 10.3832/ifor2801-012 [online 2019-04-25]

Communicated by: Rossella Guerrieri al. 2013) or negative effects (Trubat et al. 2008, Zida et al. 2008, Cortina et al. 2013, Ivetic et al. 2016) or both (Navarro et al. 2006) on planting performance.

These contradictory results stem from the excessive dependence of performance on study conditions: although the outcome of the trade-off between root growth (a large seedling implies more root growth) and transpiration rate (higher in larger shoots) in dry areas depends to a large extent on soil moisture at transplanting (Grossnickle 2012), there are also other environmental factors, such as wind, temperature and solar radiation, which should be borne in mind. Forestation experiments under field conditions in dry areas often do not provide clear evidence because the aforementioned environmental factors override the effect of plant size. As a consequence, our ability to predict seedling survival in drylands is still poor (Cortina et al. 2013). We believe that in order to validate and generalize models there is a need for experimental evidence based on the comparison of large vs. small seedlings under controlled soil moisture conditions. This could help to explain which circumstances lead to small seedlings having a more favorable response (Pinto et al. 2011). Experiments assessing the interaction between soil moisture and seedling size when planting containerized seedlings are still few in the literature (Rose et al. 1993, Stewart \& Bernier 1995, Lamhamedi et al. 1997, Jutras et al. 2007, Villar-Salvador et al. 2013a, Walsh et al. 2014), and those carried out did not simultaneously analyze seed- 
ling root growth and water status. Most of these studies have been designed in such a way that seedling size factor is confounded with the stock type (i.e., bareroot vs. container), container shape, plant age or hardening treatments. Root growth right after planting is critical for minimizing transplant shock (Grossnickle 2005) and surviving the dry soil season (Villar-Salvador et al. 2012). Assessing the root growth of different stock sizes under a gradient of soil moisture would help to explain the response of planted seedlings under drought stress. Accordingly, the aim of this experiment was to provide a physiological basis for the selection of the most appropriate seedling size for planting in dry areas, with the following specific objectives in mind: (i) to compare large vs. small seedling water potential during the first weeks (30 days) after planting in drought conditions vs. field capacity levels; (ii) to assess the root growth of large vs. small seedlings as affected by soil moisture at planting. We hypothesize that: (1) freshly planted large seedlings under drought conditions will be more water stressed than small seedlings; and (2) the root growth of large seedlings will be reduced under dry conditions. In summary, this study examines the shortterm performance of two seedling sizes (large and small) planted in a greenhouse controlled experiment under two soil moisture regimes.

\section{Materials and methods}

Plant material and planting experiment

The plant material was obtained from seedlings produced in $230 \mathrm{~cm}^{3}$ containers (SuperLeach $^{\mathrm{TM}}$, Industrias Bardi S.A.L., Navarre, Spain) filled with a 3:1 (v:v) Sphagnum peat (Kekkilä Bo, Finland) and perlite mixture with $5 \mathrm{~g} \mathrm{I}^{-1}$ of Osmocote Plus 15-11$13+2 \mathrm{MgO}$ controlled release fertilizer (Scotts, Marysville, OH, USA). Containerized seedlings were chosen as they are most commonly used in dry planting areas (Grossnickle \& El-Kassaby 2016). Seeds from Pinus canariensis Chr. Sm. ex DC - a native species from the Canary Islands that thrives in dry areas (Luis et al. 2013) - were sown in April and May 2013 using the same seed lot. From May to the end of October, the seedlings remained outdoors at the
School of Forestry's nursery, Madrid, Spain (lat. $40^{\circ} 27^{\prime} 06^{\prime \prime} \mathrm{N}$, long. $03^{\circ} 43^{\prime} 23^{\prime \prime} \mathrm{W}$, elevation $657 \mathrm{~m}$ a.s.l.). On $30^{\text {th }}$ October 2013, 30 seedlings of each size were selected for the study sample. The small seedlings were chosen from among the population of $P$. canariensis sown in May, whereas the large ones came from the trays sown in April. The small seedlings had a height (length of stem) of between 9 and $19 \mathrm{~cm}$ and the large seedlings between 28 and $44 \mathrm{~cm}$. The average height and coefficient of variation (CV) was $14.3 \mathrm{~cm}(\mathrm{CV}=19.8 \%)$ for the small seedlings and $33.7 \mathrm{~cm}(\mathrm{CV}=11.5 \%)$ for the large ones.

The 60 selected seedlings received a saturating irrigation on November $3^{\text {rd }}, 2013$. They were then transplanted on November $4^{\text {th }}$ to $3.5 \mathrm{I}(16 \times 22 \mathrm{~cm}$, diameter $\times$ height $)$ pots filled with a 1:2 (v:v) washed river sand and Sphagnum peat (Kekkilä Professional OPM420 Natural, Finland) mixture. Pots were randomly placed on a bench in the greenhouse, with a glass transmittance of $47 \%$, at the School of Forestry. During the experiment, the temperature was kept between 15 (night) and 25 (day) ${ }^{\circ} \mathrm{C}$. Once in the greenhouse, half of the seedlings of each size were randomly assigned to one of the two soil moisture regimes. Therefore, the experiment had a two-factor factorial design: seedling size (large and small) and soil moisture (dry and wet). The volumetric water content (VWC) of the growing medium was maintained at $7 \%$ (dry) and 15\% (wet) throughout the study period. The $7 \%$ target corresponds to soil moisture values at a depth of $0-15 \mathrm{~cm}$ in dry areas during the planting season (Oliet et al. 2002). This value causes a high level of water stress that significantly reduces seedling stomatal conductance and photosynthesis in peat-based substrates (Stewart \& Bernier 1995, Quero et al. 2006). In contrast, $15 \%$ corresponds to the field capacity of the peat-sand growing medium employed. This was achieved by saturating the pots and letting the water percolate through the bottom holes (personal observation).

\section{Measurements}

To maintain the target levels of soil moisture, the VWC of each pot's medium was measured immediately after transplanting

Tab. 1 - ANOVA results and mean values ( \pm standard error) of soil volumetric water content (VWC) as affected by seedling size and soil moisture regime $(n=30$ per factor level) 10 days after transplanting. ANOVA was conducted with log transformed data, but back transformed VWC means are presented for clarity.

\begin{tabular}{lcclc}
\hline Source of variation & $\mathbf{F}$ & $\boldsymbol{P}>\mathbf{F}$ & $\begin{array}{l}\text { Seedling size/ } \\
\text { Treatment }\end{array}$ & $\begin{array}{c}\text { Soil VWC } \\
\mathbf{( \% )}\end{array}$ \\
\hline Seedling size (SS) & 1.544 & 0.219 & Large & $11.4 \pm 0.8$ \\
& & & Small & $12.2 \pm 0.8$ \\
Soil moisture (SM) & 116.402 & $<0.001$ & $\begin{array}{l}\text { Dry } \\
\text { Wet }\end{array}$ & $8.3 \pm 0.3$ \\
SS $\times$ SM & & & Wet & $15.3 \pm 0.6$ \\
\hline
\end{tabular}

by using time domain reflectometry (TDR) with a Hydrosense $\mathrm{CS}_{22}{ }^{\oplus}$ Water Content Reflectometer (Campbell Scientific Inc., USA). A pair of $20-\mathrm{cm}$ rods were vertically inserted twice from the top of the pots and the measurements averaged. Following this, the water volume required to restore the moisture target level of the potting medium was added. The VWC was measured again after drainage (when this occurred) and new amounts of water were added (when necessary) in a trial and error process. Once the VWC had reached the target value, the pots were weighed and the reference weight for each pot and its soil moisture level were recorded. Successive irrigations were conducted using a gravimetric procedure (Heiskanen \& Rikala 1998). The pots were weighed every two days and water was added as needed to meet the target weight. The gravimetric approach was preferred over TDR to avoid possible damage to protruding roots and alterations in the growing medium structure due to the repeated rod insertions. In order to check that the VWC was within the target values throughout the experiment, 10 days after planting (November 13) TDR measurements were taken again in all the pots. The deviation from the VWC target was minimum, with significant differences by soil moisture treatment but not by seedling size or interactions (Tab. 1). This is particularly important in experiments of this type in which a regression artefact can occur because transpiration rates vary according to shoot size, thus affecting soil moisture (Rose et al. 1993).

The study period covered the first weeks after planting in which the first roots protrude from the plug and their subsequent coupling with the soil-atmosphere system occurs (Grossnickle 2005). The response variables evaluated were root growth and shoot water potential. Both were measured simultaneously twice during the experiment. Water potential was chosen as a surrogate of water stress that may occur when transpiration demand exceeds the ability of root systems to uptake and transport water (Cruiziat et al. 2002). To characterize the water stress levels of the seedlings, midday xylem water potential was measured twice: 10 days after planting (DAP), before the protrusion of any root from the plug; and $30 \mathrm{DAP}$, when the seedlings had developed a significant amount of root tissue outside the plug. Midday water potential $\left(\psi_{\mathrm{MD}}\right)$ was measured in six (10 DAP) or eight-nine (30 DAP) randomly selected seedlings per treatment (factor combination) as follows: at 14:00h, the shoots of all the pine seedlings were excised from the root collar diameter and stored in plastic bags in a cooler until measurement. Shoot water potential was measured within one hour in a pressurized chamber (Model $600^{\circledast}$, PMS Instruments, Inc., Corvallis, OR, USA). Midday water potential was chosen because it closely reflects the maximum values of water stress 
in plants during a daily cycle (Bernier 1993, Kavanagh \& Zaerr 1997, Lambers et al. 2008). Root development can also affect the ability to transport water to seedlings and, in turn, plant water status. Thus, plugs of the same seedlings used for water potential measurements were lifted from the pots to assess the length of new root growth. At $10 \mathrm{DAP}$, no roots longer than $0.5 \mathrm{~cm}$ had protruded from the plugs. One month after planting, all new roots protruding from the plug were excised and their total length was measured with a ruler. Additionally, seedling dry mass from the 30 DAP water potential assessment was measured after carefully washing root systems (excluding new protruding roots) to remove the medium and oven drying roots and shoots for $48 \mathrm{~h}$ at $65^{\circ} \mathrm{C}$.

\section{Data analysis}

A two-way analysis of variance (ANOVA) was performed on the data, with soil moisture and seedling size as fixed factors and a seedling serving as the experimental unit. Data homocedasticity was checked using Levenne's test. When the ANOVA assumptions were not met (VWC, midday water potential, root and shoot biomass 30 DAP and new root length), the data were logtransformed. When the ANOVA showed significance for the interaction between factors, the differences among means were identified by a Tukey post-hoc test. Effects were considered significant when $P<0.05$. Throughout this work, the significance level for each ANOVA $(P)$ is presented with degrees of freedom for each factor $\left(d f_{1}\right)$ and for error term $\left(d f_{2}\right)$ as subscripts $\left(P_{\mathrm{df1}, \mathrm{df} 2}\right)$. All the analyses were carried out with the SPSS ${ }^{\oplus}$ ver. 19.0 statistical package (SPSS Inc., Chicago, IL, USA).

\section{Results}

On average, the $\psi_{\mathrm{MD}}$ of seedlings transplanted in humid soil decreased from -1.10 \pm 0.05 (SE) to $-1.45 \pm 0.05 \mathrm{MPa}$ and in dry soil from $-1.00 \pm 0.05$ to $-1.83 \pm 0.11 \mathrm{MPa}$ between the $10^{\text {th }}$ and the $30^{\text {th }} \mathrm{DAP}$, respectively. However, the variation pattern of this trait by factor was date dependent (Tab. 2). While in the $10^{\text {th }}$ DAP no significant differences were found in soil moisture, seedling size or interactions (Fig. 1a), by 30 DAP the measured $\psi_{\text {MD }}$ was significantly affected by seedling size $\times$ soil moisture interaction. The large seedlings planted in the dry substrate for at least 30 days were more stressed than the small seedlings under the same soil conditions. On the other hand, the $\psi_{M D}$ of the seedlings planted for 30 days in wet conditions was unaffected by their size and was not significantly different from that of the small seedlings planted in dry soil (Fig. 1b).

No significant root growth had occurred 10 DAP (as revealed by seedlings extracted at this date for water potential measurements - data not shown), but after 30 days root growth protruding from the plugs was noticeable. Interestingly, by this time the
Tab. 2 - ANOVA results for midday water potential prior (10 DAP) and after (30 DAP) new root growth outside the plug, and length of new roots outside the plug 30 DAP in relation to seedling size and soil moisture regime. $\left({ }^{*}\right)$ : For midday water potential 30 DAP and new root length, ANOVA was conducted with log transformed data.

\begin{tabular}{llcc}
\hline Variable & Source of variation & $\mathbf{F}$ & $P>\mathbf{F}$ \\
\hline Midday water potential $\left(\Psi_{\text {MD }}\right)$ & Seedling size $(S S)$ & 0.624 & 0.439 \\
10 DAP $\left(d f_{1}=1 ; d f_{2}=20\right)$ & Soil Moisture $(S M)$ & 2.306 & 0.145 \\
& SS $\times$ SM & 0.181 & 0.675 \\
\hline Midday water potential $\left(\psi_{\text {MD }}\right)$ & Seedling size $(S S)$ & 5.382 & 0.027 \\
30 DAP* $\left(d f_{1}=1 ; d f_{2}=30\right)$ & Soil Moisture (SM) & 0.001 & 0.001 \\
& SS $\times$ SM & 4.371 & 0.045 \\
New root length & Seedling size (SS) & 9.598 & 0.006 \\
30 DAP* $\left(d f_{1}=1 ; d f_{2}=20\right)$ & Soil Moisture (SM) & 0.013 & 0.912 \\
& SS $\times$ SM & 1.576 & 0.224 \\
\hline
\end{tabular}

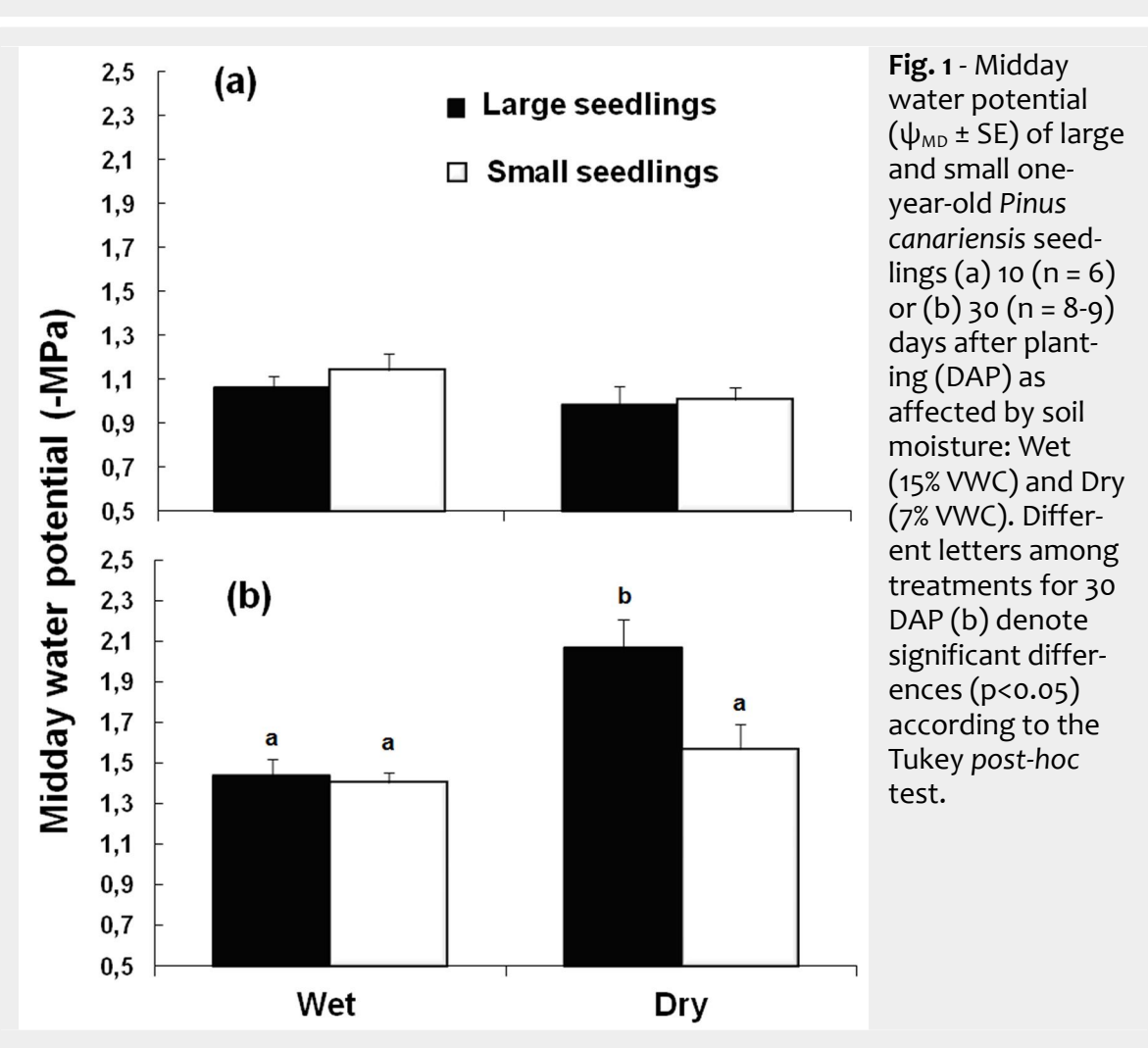

total length of these emerging roots was biomass 30 DAP was affected by seedling only significantly affected by seedling size size $\left(P_{1,28}<0.001\right.$, data log-transformed), (Tab. 2), with the large seedlings producing but not by soil moisture or its interactions. longer roots (Fig. 2). The shoot or root At this point, the shoot and root biomass

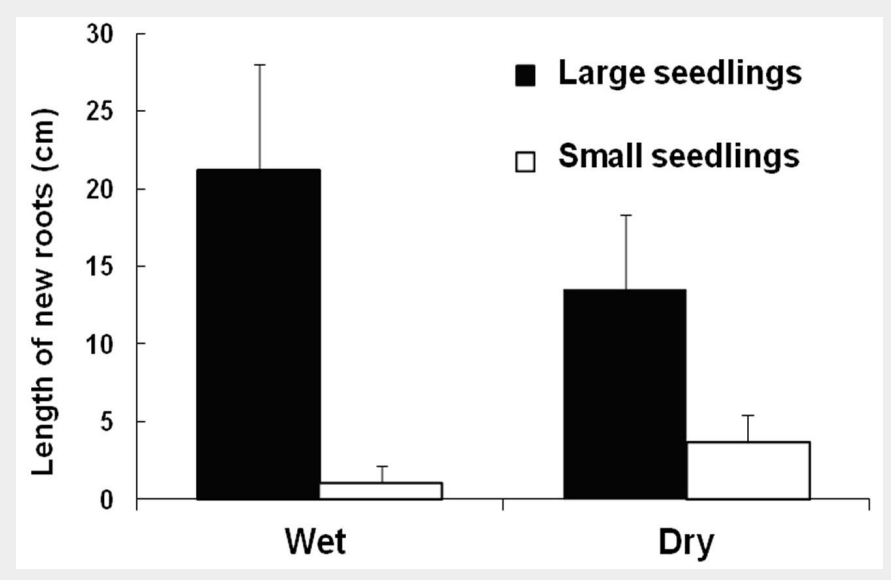

Fig. 2 - Length of new roots $( \pm S E, n$ $=6$ ) of large and small one-year-old Pinus canariensis seedlings protruding from the plug 30 days after planting under different soil moisture conditions: Wet (15\% VWC) and dry ( $7 \%$ VWC). According to Tab. 2 , only seedling size is significant. 
of the large seedlings ( $1.5 \pm 0.1$ and $2.4 \pm 0.2$ $\mathrm{g}$, respectively) was three times greater than that of the small seedlings $(0.5 \pm 0$. and $0.8 \pm 0.1 \mathrm{~g}$, respectively). By then, a sig nificant seedling size $\times$ soil moisture inter action had occurred for the shoot/root ratio $\left(P_{1,28}=0.022\right)$, with all ratios being similar ( $0.65 \pm 0.03$ on average) except for the small seedlings planted in wet soils, whose ratio dropped to $0.42 \pm 0.06$.

\section{Discussion}

This study indicates that seedling size affects water stress levels after planting, but this effect is soil moisture dependent. Under dry soil conditions, the large seedlings showed high levels of water stress. Other field or controlled experiments have substantiated this relationship between seedling size and water stress (Lamhamedi et al. 1998, Ovalle et al. 2016), but only a few of them have analyzed how the relationship between seedling size and soil moisture impacts $\psi_{\mathrm{MD}}$ (Stewart \& Bernier 1995, Lamhamedi et al. 1997). Furthermore, the controlled conditions experiment performed here shows that large seedlings are not more stressed during the first weeks after planting than small ones if soil moisture is high. It also provides an experimental basis for the model constructed by Villar-Salvador et al. (2012), stating that large containerized seedlings do not experience planting shock, provided that the soil is moist. Moving on, the results obtained here show that during the first 10 DAP, seedling water status was unaffected by seedling size, soil moisture or its interaction, despite the significant differences in soil VWC at the time (Tab. 1). This indicates the positive role of a saturated plug in reducing immediate planting shock (Grossnickle \& El-Kassaby 2016) even under dry postplanting conditions. However, this effect is ephemeral: water either diffuses through the saturated plug to the adjacent soil (Heiskanen \& Rikala 2000) or is taken up by the roots within the plug. This depletion of water reserves was reflected in the water potential reduction of seedlings from 10 to 30 DAP even in wet soil (Fig. 1 and Results). In a similar experiment, containerized seedlings under dry conditions also took four weeks to reach a significantly lower water potential than seedlings under well-watered conditions (Jutras et al. 2007). The rate at which plug water reserves are depleted will depend not only on the transpiration demand of the seedlings, but also on soil water content. Dry soils will generate a more intense water potential gradient from plug to soil or substrate (Stewart \& Bernier 1995, Heiskanen \& Rikala 2000). Our results also underline the relevance of shoot size over shoot/root ratio for water balance at the planting stage. The higher evaporative demands of larger shoots are not offset by larger root systems within the plug. This agrees with other studies that have played down the importance of the shoot/root ratio as an estimator of water stress avoidance for containerized seedlings (Grossnickle 2012 and references therein). Regardless of the root system size or the new growth of roots protruding from the plug, large shoot seedlings planted in dry soils will be more prone to suffer from water stress than small ones, as they deplete plug water reserves sooner. Moreover, coarse-textured soils have a lower conductance than fine-textured ones when water is scarce (McDowell et al. 2008). Thus, a higher level of water stress can be expected when planting takes place in coarse textured dry soils such as the potting medium employed in this study (Bernier \& González 1995).

The new root growth of the large seedlings during the first weeks of establishment was higher than that of the small seedlings, irrespective of soil moisture. Therefore, soil moisture did not limit the root growth of the large seedlings during the study period. The depleting effect of soil drought on root growth could take longer to become significant; this effect was detected after eight weeks in a controlled experiment with Pinus taeda L. (Torreano \& Morris 1998). Under water scarcity, root growth can be inhibited by, among other factors, high water stress levels in the plant that preclude cell division (Lambers et al. 2008) and carbon gain (Villar-Salvador et al. 2015). As shown by the root growth rates of the large seedlings in the dry soils used in this study, the $\psi_{\mathrm{MD}} 30$ DAP was not yet so low as to preclude stomata closure and cell division, despite the low soil moisture of the $7 \%$ VWC treatment. The soil water potential limit at which plants are able to regenerate new roots after transplanting depends to a great extent on soil moisture, temperature (Sword Sayer et al. 2005) and the species (Kaushal \& Aussenac 1989).

According to the literature, the swiftness with which seedlings are able to establish new roots in the soil is key to reducing water stress and transplant shock (Grossnickle 2005, Villar-Salvador et al. 2012). However, it has been shown here that this is not the case with the largest seedlings under drought conditions, since they produce more new roots than smaller sized ones but, at the same time, register the lowest $\psi_{M D}$. Large seedlings can produce more roots and reduce water stress after transplanting, but only if soil moisture is high (Hines \& Long 1986, Kavanagh \& Zaerr 1997). In this study, the water requirements of the large seedlings was not offset by the improved uptake of a new extended root system exploring dry soil and, accordingly, planting shock was not reduced as indicated by the lower values of the $\psi_{M D}$. The small seedlings planted in dry soils showed minimum root growth 30 DAP, but their $\psi_{M D}$ was significantly higher than that of the large seedlings and equal to that of the seedlings planted in wet conditions (Fig. 1b). This stresses the crucial role of a saturated plug to supply water during the first weeks after transplanting. Finally, as small seedlings do not grow roots neither in humid nor in dry soils, the results of this study emphasize the importance of seedling size in promoting root growth shortly after planting.

This transplanting experiment was carried out under controlled conditions in a growing medium with a low hydraulic conductivity that favored the growth of new roots. The results point to the high capacity of large seedlings to produce new roots even under dry conditions, with minimum values of $\psi_{M D}$ (maximum water stress). Field conditions involve a much more complex set of environmental factors affecting plant hydraulics and physiology than the controlled conditions of this experiment. However, the results provide some information with which to model the response of large vs. small seedlings transplanted in dry areas. Some authors claim that the success of large vs. small seedlings is dependent, among other factors, on the time between planting and the next rain event (Trubat et al. 2011, Cortina et al. 2013). Water potential decreased over the study period, but as already remarked, this drop was especially intense for large seedlings under drought conditions, despite the growth of new protruding roots. This effect makes them more prone to hydraulic failure or starvation (Kavanagh \& Zaerr 1997, McDowell et al. 2008) during the initial weeks. On the contrary, the small seedlings were more capable of reducing planting shock than the large ones, maintaining values of $\psi_{\mathrm{MD}}$ as high as those under wet conditions for at least one month. Additionally, the water potential of the large seedlings under dry conditions dropped to $-2.01 \pm 0.14 \mathrm{MPa} 30 \mathrm{DAP}$, equivalent to a $12 \%$ loss of hydraulic conductance, when embolism begins for this species (López et al. 2013). However, under field conditions, direct radiation, winds or high temperatures could increase the evaporative demands of seedling or reduce their tolerance to water stress (McDowell et al. 2008, O'Brien et al. 2014). If a rain event occurs or seedlings reach a wet soil horizon before cavitation, large seedlings could take advantage of their more developed root systems and avoid summer drought stress damage by connecting their roots to deeper, ever-moist horizons (Padilla \& Pugnaire 2007). But in a rainless scenario after planting, the specific functional water-saving or water-spending strategy of the seedling species becomes important (Lambers et al. 2008) and interacts with size. Thus, we expect that the potential negative effects of the size of seedlings on their water status may be lower in watersaver than in water-spender plants (Sakcali \& Ozturk 2004, Villar-Salvador et al. 2012, Vilagrosa et al. 2013).

\section{Conclusions}

The study results, besides providing an empirical basis, contribute to propose prac- 
tical guidelines for selecting seedlings for forestation projects in dry areas. The main idea is the overriding importance of size when planting seedlings in dry soils, with large seedlings experiencing lower water potential levels despite their larger root systems produced under dry conditions. The results of forestation in dry lands could be improved by adapting seedling size to the specific environmental conditions of the planting site, with a tendency towards using small seedlings, especially in areas with high evaporative demands at planting. Additional research should be conducted to refine the understanding of plant response under dry conditions and to achieving a better match between seedling quality and particular restoration environments. Future controlled and field studies of plant size and planting response should analyze key interactions between specific functional traits (plant hydraulics, water use strategy, foliar habits and the ability to produce new roots in dry soils) and environmental conditions at planting, specifically vapor pressure deficit and certain soil characteristics (texture, water retention capacity and hydraulic conductance).

\section{Acknowledgments}

The study was supported by the AGL201124296 ECOLPIN project (Department of Science and Innovation, Spanish Government) and the PhD educational program of the Technical University of Madrid, Spain.

\section{Author contributions}

JAO conceived and designed the research; EOU, MSP, GTC performed the experiments, JAO, EOU, MSP, GTC analyzed the data; JAO wrote the manuscript; MSP, GTC edited the manuscript.

\section{References}

Bernier PY (1993). Comparing natural and planted back spruce seedlings. I. Water relations and growth. Canadian Journal of Forest Research 23: 2427-2434. - doi: 10.1139/x93-300 Bernier PY, González A (1995). Effects of the physical properties of sphagnum peat on the nursery growth of containerized Picea mariana and Picea glauca seedlings. Scandinavian Journal of Forest Research 10: 184-189. - doi: 10.1080 /02827589509382883

Cortina J, Vilagrosa A, Trubat R (2013). The role of nutrients for improving seedling quality in drylands. New Forests 44 (5): 719-732. - doi: 10.1007/s11056-013-9379-3

Cruiziat P, Cochard H, Ameglio T (2002). Hydraulic architecture of trees: main concepts and results. Annals of Forest Science 59: 723-752. doi: 10.1051/forest:2002060

Dumroese RK, Landis TD, Pinto JR, Haase DL, Wilkinson KW, Davis AS (2016). Meeting forest restoration challenges: using the target plant concept. Reforesta 1: 37-52. - doi: 10.21750/RE FOR.1.03.3

Grossnickle S, El-Kassaby YA (2016). Bareroot versus container stocktypes: a performance comparison. New Forests 47: 1-51. - doi: 10.1007/ s11056-015-9476-6
Grossnickle SC (2005). Importance of root growth in overcoming planting stress. New Forests 30: 273-294. - doi: 10.1007/s11056-0048303-2

Grossnickle SC (2012). Why seedlings survive: influence of plant attributes. New Forests 43: 711738. - doi: 10.1007/s11056-012-9336-6

Heiskanen J, Rikala R (1998). Influence of different nursery container media of Scots pine and Silver birch seedling after transplanting. New Forests 16: 27-42. - doi: 10.1023/A:10065838311 89

Heiskanen J, Rikala R (2000). Effect of peatbased container media on establishment of Scots pine, Norway spruce and Silver birch seedlings after transplanting in contrasting water conditions. Scandinavian Journal of Forest Research 15 (1): 49-57. - doi: 10.1080/02827580 050160466

Hines FD, Long JN (1986). First and second year survival of containerized Engelmann spruce in relation to seedling size. Canadian Journal of Forest Research 16: 668-670. - doi: 10.1139/×86117

Ivetic V, Grossnickle S, Skoric M (2016). Forecasting the field performance of Austrian pine seedlings using morphological attributes. iForest 10: 99-107. - doi: 10.3832/ifor1722-009

Jutras S, Thiffault N, Munson AD (2007). Comparing large bareroot and container stock: water stress as influenced by peat and soil water availability. Tree Planters' Notes 52: 15-18.

Kaushal P, Aussenac G (1989). Transplanting shock in Corsican Pine and Cedar of Atlas seedlings: internal water deficits, growth and root regeneration. Forest Ecology and Management 27: 29-40. - doi: 10.1016/0378-1127(89)90080-7

Kavanagh KL, Zaerr JB (1997). Xylem cavitation and loss of hydraulic conductance in Western hemlock following planting. Tree Physiology 17: 59-63. - doi: 10.1093/treephys/17.1.59

Lambers H, Chapin FS, Pons TJ (2008). Plant physiological ecology $\left(2^{\text {nd }}\right.$ edn). Springer, New York, USA, pp. 694.

Lamhamedi MS, Bernier PY, Hébert C (1997). Effect of shoot size on the gas exchange end growth of containerized Picea mariana seedlings under different watering regimes. New Forests 13: 209-223. - doi: 10.1023/A:100658632 5524

Lamhamedi MS, Bernier PY, Hébert C, Jobidon R (1998). Physiological and growth responses of three sizes of containerized Picea mariana seedlings outplanted with and without vegetation control. Forest Ecology and Management 110: 13-23. - doi: 10.1016/S0378-1127(98)00267-9

López R, López De Heredia U, Collada C, Cano FJ, Emerson BC, Cochard H, Gil L (2013). Vulnerability to cavitation, hydraulic efficiency, growth and survival in an insular pine (Pinus canariensis). Annals of Botany 111: 1167-1179. - doi: 10.109 3/aob/mcto84

Luis VC, Pérez-Martín E, Velázquez C, Naranjo B (2013). Pinus canariensis Chr. Sm. ex DC. In: "Producción y Manejo de semillas y plantas forestales" [Production and handling of forest seeds and seedlings] (Pemán García J, Navarro Cerrillo RM, Nicolás Peragón JL, Prada Sáez MA, Serrada Hierro R eds). Naturaleza y Parques Nacionales, Serie Forestal, Ministerio de Agricultura, Alimentación y Medio Ambiente,
Spain, vol. l, pp. 841-854.

McDowell N, Pockman WT, Allen CD, Bershears DD, Cobb N, Kolb T, Plaut J, Sperry J, West A, Williams DG, Yepez EA (2008). Mechanisms of plant survival and mortality during drought: why do some plants survive while others succumb to drought? New Phytologist 178: 719739. - doi: 10.1111/j.1469-8137.2008.02436.x Navarro R, Villar-Salvador P, Del Campo A (2006). Morfología y establecimiento de los plantones [Morphology and establishment of seedlings]. In: "Calidad de planta forestal para la restauración en ambientes mediterráneos degradados. Estado actual de conocimientos" [Seedling quality for restoration of degraded Mediterranean environments. Current knowledge] (Cortina J, Peñuelas JL, Puértolas J, Savé J, Vilagrosa A eds). Organismo Autónomo Parques Nacionales, Ministerio de Medio Ambiente, Madrid, Spain, pp. 67-88.

O'Brien MJ, Leuzinger S, Philipson CD, Tay J, Hector A (2014). Drought survival of tropical tree seedlings enhanced by non-structural carbohydrate levels. Nature Climate Change 4: 710714. - doi: $10.1038 /$ nclimate2281

Oliet JA, Planelles R, López Arias M, Artero F (2002). Soil water content and water relations in planted and naturally regenerated Pinus halepensis Mill. Seedlings during the first year in semiarid conditions. New Forests 23: 31-44. doi: 10.1023/A:1015668815037

Oliet JA, Puértolas J, Planelles R, Jacobs DF (2013). Nutrient loading of forest tree seedlings to promote stress resistance and field performance: a Mediterranean perspective. New Forests 44: 649-669. - doi: 10.1007/s11056-013-93828

Ovalle J, Arellano E, Oliet J, Becerra P, Ginocchio $R$ (2016). Linking nursery nutritional status and water availability post-planting under intense summer drought: the case of a South American Mediterranean tree species. iForest 9: 758-765. - doi: 10.3832/ifor1905-009

Padilla FM, Pugnaire FI (2007). Rooting depth and soil moisture control Mediterranean woody seedling survival during drought. Functional Ecology 21: 489-495. - doi: 10.1111/j.13652435.2007.01267.x

Pinto JR, Dumroese KD, Davis A, Landis T (2011). Conducting seedling stocktype trials: a new approach to an old question. Journal of Forestry 109: 293-299. [online] URL: http://academic. oup.com/jof/article/109/5/293/4599473

Piñeiro J, Maestre FT, Bartolomé L, Valdecantos A (2013). Ecotechnology as a tool for restoring degraded drylands: a meta-analysis of field experiments. Ecological Engineering 61: 133-144. doi: 10.1016/j.ecoleng.2013.09.066

Puértolas J, Jacobs DF, Benito LF, Peñuelas JL (2012). Cost-benefit analysis of different container capacities and fertilization regimes in $\mathrm{Pi}$ nus stock-type production for forest restoration in dry Mediterranean areas. Ecological Engineering 44: 210-215. - doi: 10.1016/j.ecoleng.20 12.04.005

Quero J, Villar R, Marañón T, Zamora R (2006). Interactions of drought and shade effects on seedlings of four Quercus species: physiological and structural leaf responses. New Phytologist 170: 819-834. - doi: 10.1111/j.1469-8137.2006.0171 $3 . x$ 
Rose R, Gleason JF, Atkinson M (1993). Morphological and water-stress characteristics of three Douglas-fir stocktypes in relation to seedling performance under different soil moisture conditions. New Forests 7: 1-17. - doi: 10.1007/BFoo 037468

Sakcali MS, Ozturk M (2004). Eco-physiological behaviour of some Mediterranean plants as suitable candidates for reclamation of degraded areas. Journal of Arid Environments 57: 1-13. - doi: 10.1016/S0140-1963(03)00099-5

Stewart JD, Bernier PY (1995). Gas exchange and water relations of 3 sizes of containerized Picea mariana seedlings subjected to atmospheric and edaphic water stress under controlled conditions. Annals of Forest Science 52: 1-9. - doi: 10.1051/forest:19950101

Sword Sayer MA, Brissette JC, Barnett JP (2005). Root growth and hydraulic conductivity of Southern pine seedlings in response to soil temperature and water availability after planting. New Forests 30: 253-272. - doi: 10.1007/s11 056-005-7481-x

Torreano SJ, Morris LA (1998). Loblolly pine root growth and distribution under water stress. Soil Science Society of America Journal 62: 818827. - doi: 10.2136/sssaj1998.0361599500620003 0040x

Trubat R, Cortina J, Vilagrosa A (2008). Shortterm nitrogen deprivation increases field performance in nursery seedlings of Mediterranean woody species. Journal of Arid Environ- ments 72: 879-890. - doi: 10.1016/j.jaridenv.2007 .11 .005

Trubat R, Cortina J, Vilagrosa A (2010). Nursery fertilization affects seedling traits but not field performance in Quercus suber L. Journal of Arid Environments 74: 491-497. - doi: 10.1016/j.jarid env.2009.10.007

Trubat R, Cortina J, Vilagrosa A (2011). Nutrient deprivation improves field performance of woody seedlings in a degraded semi-arid shrubland. Ecological Engineering 37: 1164-1173. - doi: 10.1016/j.ecoleng.2011.02.015

Tsakaldimi M, Ganatsas P, Jacobs DF (2013). Prediction of planted seedling survival of five Mediterranean species based on initial seedling morphology. New Forests 44 (3): 327-339. - doi: 10.1007/s11056-012-9339-3

Vallejo RV, Smanis A, Chirino E, Fuentes D, Valdecantos A, Vilagrosa A (2012). Perspectives in dryland restoration: approaches for climate change adaptation. New Forests 43 (5-6): 561579. - doi: 10.1007/s11056-012-9325-9

Vilagrosa A, Hernández EI, Luis VC, Cochard H, Pausas JG (2013). Physiological differences explain the co-existence of different regeneration strategies in Mediterranean ecosystems. New Phytologist 201: 1277-1288. - doi: 10.1111/nph.12 584

Villar-Salvador P, Puértolas J, Cuesta B, Peñuelas $J$, Uscola M, Heredia-Guerrero N, Rey Benayas JM (2012). Increase in size and nitrogen concentration enhances seedling survival in Mediter- ranean plantations. Insights from an ecophysiological conceptual model of plant survival. New Forests 43: 755-770. - doi: 10.1007/s11056-0129328-6

Villar-Salvador P, Peñuelas JL, Jacobs DF (2013a). Nitrogen nutrition and drought hardening exert opposite effects on the stress tolerance of Pinus pinea L. seedlings. Tree Physiology 33 (2): 221-232. - doi: 10.1093/treephys/tps133

Villar-Salvador P, Peñuelas JL, Nicolás-Peragón JL, Benito LF, Domínguez S (2013b). Is nitrogen fertilization in the nursery a suitable tool for enhancing the performance of Mediterranean oak plantations? New Forests 44 (5): 733-751. doi: 10.1007/s11056-013-9374-8

Villar-Salvador P, Uscola M, Jacobs DF (2015). The role of stored carbohydrates and nitrogen in the growth and stress tolerance of planted forest trees. New Forests 46 (5): 813-839. - doi: 10.1007/s11056-015-9499-z

Walsh D, Rossi S, Lord D (2014). Size and age: intrinsic confounding factors affecting the responses to a water deficit in black spruce seedlings. iForest 8: 401-409. - doi: 10.3832/ifor1412007

Zida D, Tigabu M, Sawadogo L, Odén PC (2008). Initial seedling morphological characteristics and field performance of two Sudanian savanna species in relation to nursery production period and watering regimes. Forest Ecology and Management 255: 2151-2162. - doi: 10.1016/j.for eco.2007.12.029 